\title{
Expanded polytetrafluoroethylene conduits and patches with bulging sinuses and fan-shaped valves in right ventricular outflow tract reconstruction: Multicenter study in Japan
}

\author{
Takako Miyazaki, MD, PhD, ${ }^{\text {a }}$ Masaaki Yamagishi, MD, PhD, ${ }^{\mathrm{a}}$ Yoashinobu Maeda, MD, ${ }^{\mathrm{a}}$ \\ Yusuke Yamamoto, MD, ${ }^{a}$ Satoshi Taniguchi, MD, ${ }^{a}$ Yuji Sasaki, MD, ${ }^{\mathrm{a}}$ and Hitoshi Yaku, MD, PhD ${ }^{\mathrm{b}}$
}

\begin{abstract}
Objective: There is no optimal substitute for right ventricular outflow tract (RVOT) reconstruction in congenital heart defects. Expanded polytetrafluoroethylene (ePTFE) valved conduits and patches may be a good alternative to homografts and bovine jugular veins. We have developed a fan-shaped ePTFE valve and an ePTFE valved conduit and patch with bulging sinuses with the aim of enhancing the long-term valve function.
\end{abstract}

\begin{abstract}
Method: Bulging sinuses were constructed on ePTFE conduits and patches as described previously ( $\mathrm{J}$ Thorac Cardiovasc Surg. 2007;134:327-32). Between February 2001 and January 2011, 794 patients (aged 14 days to 56.8 years old; median, 2.0 years old) had ePTFE valves implanted for RVOT reconstruction at 52 Japanese institutes. Conduits with a fan-shaped ePTFE valve were implanted in 325 patients and a patch with a fan-shaped ePTFE valve was implanted in 469 patients. Valve function was assessed by a series of echocardiograms postoperatively.
\end{abstract}

Results: The mean follow-up was 3.6 years (1.1 months to 10.0 years). Freedom from reoperation at 10 years was $95.4 \%$ in patients with conduits and $92.3 \%$ in those with patches. Pulmonary insufficiency was mild or nonexistent in $95.0 \%$ of patients with conduits and $79.6 \%$ of patients with patches. The pressure gradient between the right ventricle and the pulmonary artery was $14.0 \pm 13.2 \mathrm{~mm} \mathrm{Hg}$ in patients with conduits and $11.6 \pm 11.6$ $\mathrm{mm} \mathrm{Hg}$ in patients with patches.

Conclusions: Fan-shaped ePTFE valved conduits and patches with bulging sinuses have a high freedom from reoperation and prevent pulmonary insufficiency. They represent a promising material for RVOT reconstruction. (J Thorac Cardiovasc Surg 2011;142:1122-9)

Video clip is available online.

Right ventricular outflow tract (RVOT) reconstruction is one of the most distinctive surgical procedures in the treatment of congenital heart disease. Although many materials can be used in RVOT reconstruction, some materials may be better at promoting valve competency. Homografts and

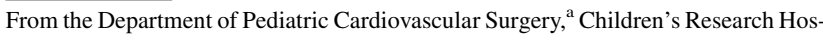
pital, Kyoto Prefectural University of Medicine; and the Division of Cardiovascular Surgery, ${ }^{\mathrm{b}}$ Department of Surgery, Kyoto Prefectural University of Medicine, Kyoto, Japan.

Disclosures: Authors have nothing to disclose with regard to commercial support.

Read at the 91st Annual Meeting of The American Association for Thoracic Surgery, Philadelphia, Pennsylvania, May 7-11, 2011.

Received for publication April 9, 2011; revisions received July 31, 2011; accepted for publication Aug 10, 2011; available ahead of print Sept 12, 2011.

Address for reprints: Masaaki Yamagishi, MD, PhD, Department of Pediatric Cardiovascular Surgery, Children's Research Hospital, Kyoto Prefectural University of Medicine, 465 Kajii-cho, Kawaramachi, Hirokoji, Kamigyo-ku, Kyoto 602-8566, Japan (E-mail: myama@koto.kpu-m.ac.jp).

$0022-5223 / \$ 36.00$

Copyright (c) 2011 by The American Association for Thoracic Surgery

doi:10.1016/j.jtcvs.2011.08.018
}

prostheses such as bovine jugular vein are standard materials for RVOT reconstruction. Homograft or bovine jugular vein offers superior pliability and good handling characteristics. In addition, bovine jugular vein can be obtained in a wide range of sizes. However, the long-term availability and durability of these materials is unsatisfactory, especially in younger children.

Because of legal problems, as well as particular regional reasons, these materials are unavailable in our country. Therefore, handmade expanded polytetrafluoroethylene (ePTFE) valves have been most commonly used. ${ }^{1-4}$ Midterm and long-term valvular function of the ePTFE valve has not been shown to be inferior to that of homograft or bovine jugular vein. Indeed, ePTFE has good biocompatibility, and its microporous structure impedes cellular penetration and subsequent calcification, which is a common cause of valvular dysfunction. Excised ePTFE valves have been found to be covered by thin fibrous tissue without evidence of calcification, and immunohistochemical analysis has revealed focal regions of endothelialization., ${ }^{2,5-7}$

$\mathrm{We}^{1,6,8}$ previously developed a fan-shaped valve made from a 0.1-mm thick ePTFE membrane (Preclude Pericardial Membrane; W.L. Gore \& Associates, Inc, Flagstaff, 


\section{Abbreviations and Acronyms}

ePTFE $=$ expanded polytetrafluoroethylene

RVOT $=$ right ventricular outflow tract

Ariz). A fan-shaped configuration of cusps with a long free margin was originally designed to prevent pulmonary regurgitation. ${ }^{8}$ Moreover, bulging sinuses were attached to ePTFE valved conduits and patches to enhance long-term valve function. ${ }^{9}$ At the initial construction of the bulging sinuses, the ePTFE graft needs to be formally opened because the bulging sinuses are formed from flat stainless molds. ${ }^{9}$ After the bulging sinus has been formed and the fanshaped valve anastomosed, the graft is rolled up and sutured to form a conduit. ${ }^{9}$ Starting in 2010, it was no longer necessary to cut open the ePTFE owing to improved fabrication techniques. The bulging sinuses are formed on the graft as depicted in Figure 1.

The fan-shaped valves are created according to a specific protocol. After formation of the bulging sinuses, the graft is turned inside out and the fan-shaped valves are sutured around the edge of the bulging sinuses (Video 1). There are 3 surgeons who complete the grafts from start to finish. Two of the surgeons created sinuses on the graft following a specific protocol, and the author (T.M.) personally sutured all the cusps on all of the conduits and the patches that were implanted in this study. The conduits and the patches were created in advance in the operating room, and all of the finished valves were sterilized at Kyoto Prefectural University of Medicine and delivered to the 52 Japanese institutes as needed.

This study was approval by the Institutional Review Board at Kyoto Prefectural University of Medicine.

\section{DATA COLLECTION AND STATISTICAL ANALYSIS}

This study was a multicenter study with each patient followed up at respective institutes. Follow-up was $100 \%$ complete with no patients lost to follow-up. Preoperative and postoperative data were collected retrospectively from the patients' medical records from each institute. The conduit diameters at the time of insertion were converted into a Z-value by regression analysis based on previously published nomograms ${ }^{10,11}$ and a predicted pulmonary valve size was determined using a historically validated nomogram ${ }^{12}$ indexed to the body surface area.

So that the presence of pulmonary regurgitation could be assessed and the mean blood pressure gradients across the valve determined, all patients periodically underwent transthoracic, 2-dimensional, color flow Doppler echocardiography in the M-mode during follow-up at each institute. The degree of pulmonary regurgitation was based on a 5 -grade semiquantitative scale $(0$, none; 1 , trivial; 2 , mild; 3 , moderate; or 4 , severe) according to features of the jet flow as measured by pulsed Doppler echocardiography. All data are expressed as mean \pm standard deviation. The KaplanMeier product limit method was used to analyze the freedom from reoperation.

\section{PATIENTS AND METHODS}

Between February 2001 and January 2011, a total of 794 patients underwent RVOT reconstruction using fan-shaped ePTFE valves and ePTFE valved conduits and patches with bulging sinuses in 52 Japanese institutes. A total of 325 patients required valved conduits (group C) and 469 patients required valved patches (group P). Conduits were chosen for patients with pulmonary atresia, truncus arteriosus, or Ross candidates who had discontinuity between the right ventricle and the pulmonary artery. Conduits were also used in adolescents and adults who needed pulmonary valve replacements. On the other hand, we used patches in cases of tetralogy of Fallot or other congenital cardiac disorders with a narrow pulmonary annulus.

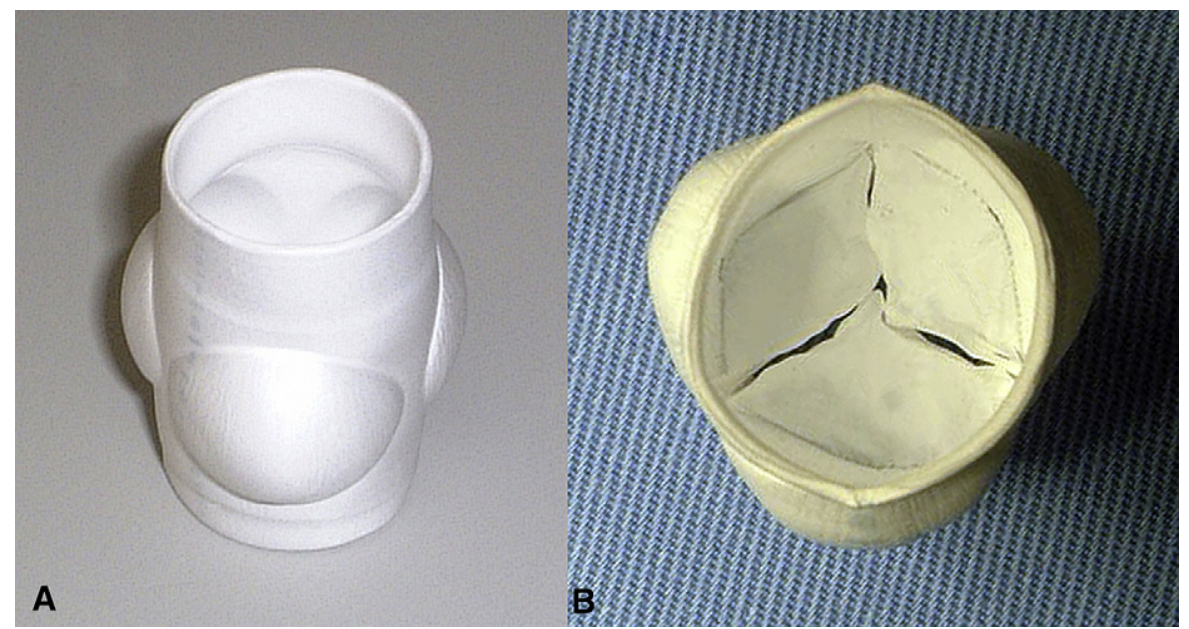

FIGURE 1. A new version of ePTFE valved conduit with bulging sinus. A, View from outside. An ePTFE conduit only with bulging sinuses; fan-shaped valves are not anastomosed yet. B, View from above. Fan-shaped valves that are anastomosed at the edge of the bulging sinuses and tightly sealed. 
TABLE 1. Anatomic diagnoses

\begin{tabular}{|c|c|c|c|}
\hline Procedure & Diagnosis & Conduit & Patch \\
\hline \multirow{10}{*}{$\begin{array}{l}\text { Construction of RV-PA } \\
\text { continuity }\end{array}$} & & 269 & 456 \\
\hline & TOF/DORV/VSD + pulm atresia & 150 & 74 \\
\hline & TOF/DORV + PS & 36 & 315 \\
\hline & $\mathrm{TOF}+\mathrm{APV}$ & 12 & 15 \\
\hline & Pulm atresia + IVS & 4 & 9 \\
\hline & $\mathrm{TGA}+\mathrm{PS}$ & 9 & 9 \\
\hline & cTGA + pulm atresia & 4 & 1 \\
\hline & $\mathrm{cTGA}+\mathrm{PS}$ & 8 & 1 \\
\hline & Truncus arteriosus & 21 & 7 \\
\hline & Others & 25 & 25 \\
\hline \multirow[t]{4}{*}{ Ross procedure } & & 56 & 13 \\
\hline & AS & 19 & 6 \\
\hline & ASR & 23 & 4 \\
\hline & AR & 14 & 3 \\
\hline \multicolumn{2}{|l|}{ Total } & 325 & 469 \\
\hline \multicolumn{4}{|c|}{$\begin{array}{l}\text { TOF, Tetralogy of Fallot; } D O R V \text {, double-outlet right ventricle; } V S D \text {, ventricular septal } \\
\text { defect; pulm atresia, pulmonary atresia; } P S \text {, pulmonary stenosis; } A P V \text {, aortopulmo- } \\
\text { nary valve; } I V S \text {, intact ventricular septum; } T G A \text {, transposition of the great arteries; } \\
c T G A \text {, corrected transposition of the great arteries; } R V \text {, right ventricle; } P A \text {, pulmonary } \\
\text { artery; } A S \text {, aortic stenosis; } A S R \text {, aortic stenosis and regurgitation; } A R \text {, aortic } \\
\text { regurgitation. }\end{array}$} \\
\hline
\end{tabular}

Autologous tissue such as pericardium was often used to reconstruct the posterior wall of the RVOT in neonates and infants who had discontinuity between the right ventricle and the pulmonary artery. The anterior wall of the RVOT was covered with the ePTFE valved patches. The anatomic diagnoses are listed in Table 1.

We attempted to position the valve at the same location as the native pulmonary annulus. When the valve had to be located at the distal position of the native pulmonary annulus (Video 2), the valve was positioned to avoid compression by the sternum. We performed RVOT reconstruction only using the ePTFE conduit and did not create a hood over the RVOT (Video 2).

The median age at the time of operation was 4.8 years old ( 15 days to 56.8 years old) in group $\mathrm{C}$ and 1.4 years ( 14 days to 45.6 years old) in group $\mathrm{P}$. There were 81 patients (24.9\%) in group $\mathrm{C}$ and 319 children $(68.0 \%)$ in group $\mathrm{P}$ younger than 2 years of age. Median body weight at the time of surgery was $13.5 \mathrm{~kg}(2.1-87.0 \mathrm{~kg})$ in group $\mathrm{C}$ and $9.0 \mathrm{~kg}(1.5-84.6 \mathrm{~kg})$ in group P. One hundred nine (33.5\%) patients in group C and $31(6.6 \%)$ in group $\mathrm{P}$ had previous RVOT reconstruction with prosthetic valves. The conduits had tricuspid valves in 317 patients, bicuspid valves in 7 patients, and a monocuspid valve in 1 patient. The diameters of the conduits were $8 \mathrm{~mm}$ (bicuspid valve) in 1 patient, $10 \mathrm{~mm}$ in 3 patients (tricuspid valve in 2 and bicuspid in 1), $12 \mathrm{~mm}$ in 10 patients (tricuspid valve in 5 patients, bicuspid in 4, and monocuspid in 1), $14 \mathrm{~mm}$ in 6 patients (tricuspid valve in 5 and bicuspid in 1), $16 \mathrm{~mm}$ in 99 patients, $18 \mathrm{~mm}$ in 75 patients, 20 mm in 9 patients, $22 \mathrm{~mm}$ in 86 patients, and $24 \mathrm{~mm}$ in 34 patients. All of the conduits in which the diameter was over $16 \mathrm{~mm}$ had tricuspid valves. Conduit size was determined by estimating $140 \%$ of the normal size of the pulmonary annulus as calculated using the formula of Rowlatt. ${ }^{12}$ Figure 2, A, shows the patients' body weight and the diameters of the conduits used, and Figure 2, $B$, shows the body weight and $\mathrm{Z}$-value. The conduit's Z-value at implantation was $1.7 \pm 1.4$ (ranging from -2.5 to 4.6 ) and its size as a percentage of the normal pulmonary annulus was $138 \% \pm 17 \%$ $(93 \%-217 \%)$. Conduit characteristics are listed in Table 2 . The Z-value at implantation was $2.4 \pm 2.1$ in patients weighing less than $5 \mathrm{~kg}$ (10 patients), $2.4 \pm 0.8$ for patients between 5 and $10 \mathrm{~kg}$ (88 patients), $1.9 \pm 0.9$ for patients between 10 and $20 \mathrm{~kg}$ ( 98 patients), and $0.0 \pm 1.0$ for patients weighing more than $20 \mathrm{~kg}$ (128 patients). Furthermore, the Z-value was $2.4 \pm 1.0$
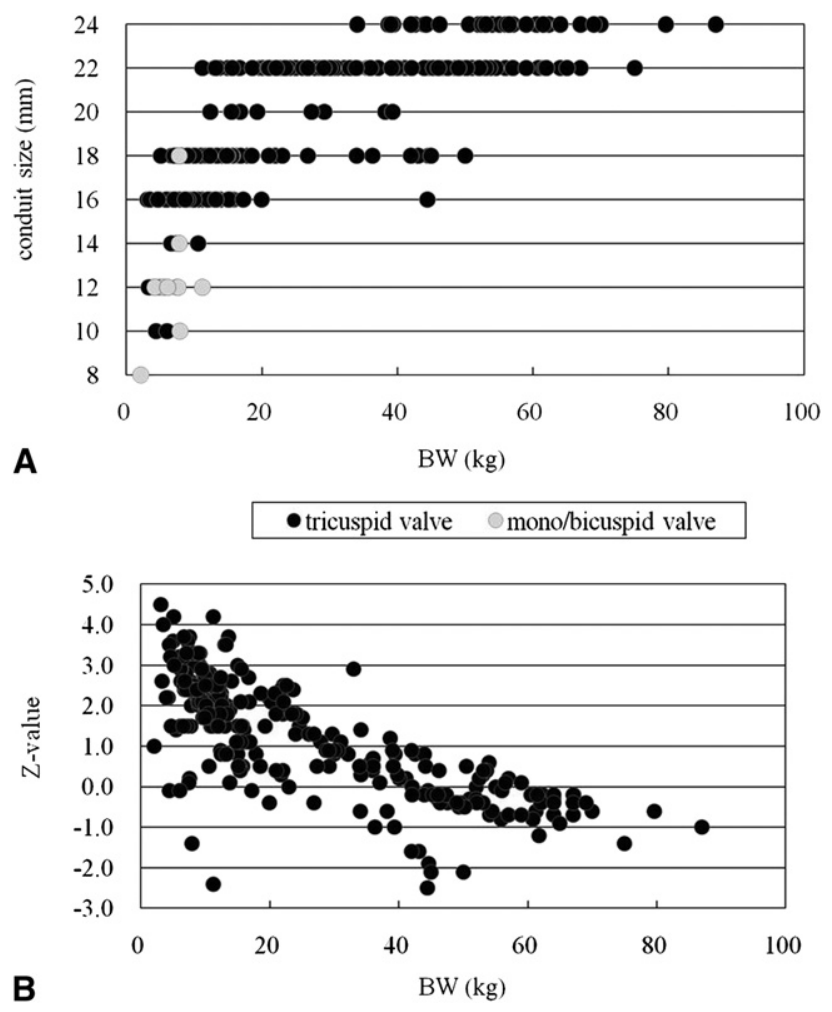

FIGURE 2. A, Patients' body weight and diameter of the conduits. B, Patients' body weight and Z-value of the conduits. $B W$, Body weight.

in patients younger than 2 years of age (81 patients), $2.1 \pm 1.0$ for patients between 2 and 5 years ( 86 patients), $1.5 \pm 0.9$ for patients between 5 and 10 years (50 patients), $0.6 \pm 1.0$ for patients between 10 and 15 years ( $47 \mathrm{pa}-$ tients), and $-0.3 \pm 0.7$ for patients older than 15 years ( 61 patients).

We previously used bicuspid or monocuspid valves for patients weighing less than $12 \mathrm{~kg}$ who needed conduits with diameters of $14 \mathrm{~mm}$ or smaller because of the difficulty in making small sinuses and small tricuspid valves that would be accommodated. However, starting in 2010 , we began making tricuspid valved conduits with diameters of 14,12 , and $10 \mathrm{~mm}$ with new fabrication techniques.

The patches had a monocuspid valve in 431 patients, bicuspid valve in 35 patients, and tricuspid valves in 3 patients. Tricuspid and bicuspid patches were used in the early series, but currently, monocuspid patches are used in almost every case. The diameter of the sinus of the patch was decided according to the size of the autologous tissue used as the posterior wall in RVOT reconstruction. That is, after RVOT reconstruction, the pulmonary annulus was $130 \%$ of normal size as calculated by the formula of Rowlatt. ${ }^{12}$

Patients were followed up for $3.6 \pm 2.2$ years (range, 1.1 month to 10.0 years). One hundred twenty-three (37.8\%) patients in group C and 297 $(63.3 \%)$ in group $\mathrm{P}$ had postoperative cardiac catheterization. From the 297 patients in group C and 397 patients in group P, confidence interval data of the most recent echocardiograms and cardiac catheterizations was obtained. No patients needed routine anticoagulation or antiplatelet therapy.

\section{RESULTS}

Echocardiography, cardiac catheterization, or magnetic resonance angiography revealed that the ePTFE leaflets were functioning well in all but 3 patients. No leaflet was 
TABLE 2. Conduit characteristics $(\mathbf{n}=\mathbf{3 2 5})$

\begin{tabular}{|c|c|c|c|c|c|}
\hline Conduit size (mm) & No. & Age & Body weight (kg) & Z-value & $\%$ of normal size \\
\hline 8 & 1 & $2.2 \mathrm{~m}$ & 2.1 & 1.0 & 125 \\
\hline 10 & 3 & $6.2 \pm 7.5 \mathrm{~m}$ & $6.0 \pm 1.8$ & $-0.1 \pm 0.8$ & $107 \pm 11$ \\
\hline 12 & 10 & $4.5 \pm 9.7 \mathrm{~m}$ & $5.3 \pm 2.3$ & $1.5 \pm 1.6$ & $130 \pm 17$ \\
\hline 14 & 6 & $1.0 \pm 1.0 \mathrm{y}$ & $7.5 \pm 1.5$ & $1.5 \pm 0.7$ & $135 \pm 7$ \\
\hline 16 & 99 & $2.1 \pm 2.5 \mathrm{y}$ & $9.5 \pm 5.7$ & $2.1 \pm 1.0$ & $139 \pm 18$ \\
\hline 18 & 77 & $3.3 \pm 9.7 \mathrm{y}$ & $12.0 \pm 9.7$ & $2.3 \pm 1.5$ & $146 \pm 19$ \\
\hline 20 & 9 & $7.2 \pm 3.7 \mathrm{y}$ & $19.3 \pm 10.2$ & $1.5 \pm 1.3$ & $141 \pm 14$ \\
\hline 22 & 86 & $13.0 \pm 7.8 \mathrm{y}$ & $36.0 \pm 15.2$ & $0.5 \pm 1.3$ & $134 \pm 14$ \\
\hline 24 & 34 & $17.6 \pm 9.2 \mathrm{y}$ & $56.0 \pm 12.1$ & $0.1 \pm 0.6$ & $135 \pm 5$ \\
\hline
\end{tabular}

completely fixed in the open position, and none had evidence of calcification or peel formation.

\section{Conduits}

There were 3 early and 5 late deaths, but these were not related to the valves. Two patients required explantation of the conduits. These 2 patients with $12-\mathrm{mm}$ conduits required reoperation at a duration of 5.7 and 5.8 years because of pulmonary stenosis secondary to their growth. Both patients received $18-\mathrm{mm}$ conduits. The degree of pulmonary regurgitation was none in $68(22.9 \%)$ patients, trivial in $134(45.2 \%)$, mild in $80(26.9 \%)$, moderate in 14 $(4.7 \%)$, and severe in only $1(0.3 \%)$ patient (Figure 3$)$. The mean peak pressure gradients between the pulmonary artery and the right ventricle were $14.0 \pm 13.2 \mathrm{~mm} \mathrm{Hg}$ (range, 0-72.9 $\mathrm{mm} \mathrm{Hg}$ ). The gradients were more than $50 \mathrm{~mm} \mathrm{Hg}$ in 8 patients, but they remained asymptomatic. Freedom from reoperation was $100 \%$ at 5 years and $95.4 \%$ at 10 years (Figure 4). Breaking down freedom from reoperation by conduit diameter, 8 - to $16-\mathrm{mm}$ diameters were $100 \%$ free at 5 years and $72.9 \%$ free at 6 years, whereas 18 - to $24-\mathrm{mm}$ diameters were $100 \%$ free at 10 years (Figure 4).

Two female patients who underwent the Ross procedure using 24-mm conduits were delivered of babies 32 and 53 months after the operation.

\section{Patches}

There were 6 early and 6 late deaths in patients receiving patches, but no deaths were related to the valves. Six patients required explantation of the patches at a duration of $3.3 \pm 2.4$ years (2.2-8.4 years). Four patients required reRVOT reconstruction because of RVOT stenosis and 2 patients needed replacement for valvular insufficiency. Four patients underwent reRVOT reconstruction using valved conduits. The degree of pulmonary regurgitation was none in $34(8.6 \%)$ patients, trivial in $89(22.4 \%)$, mild in $193(48.6 \%)$, moderate in $76(19.1 \%)$, and severe in 5 $(1.3 \%)$ patients (Figure 3$)$. The mean peak pressure gradients between the pulmonary artery and the right ventricle were $11.6 \pm 11.6 \mathrm{~mm} \mathrm{Hg}$ (range, $0-67.9 \mathrm{~mm} \mathrm{Hg}$ ). The gradients were more than $50 \mathrm{~mm} \mathrm{Hg}$ in 4 patients, but they remained asymptomatic. Freedom from reoperation was $98.6 \%$ at 5 years and $92.3 \%$ at 10 years (Figure 4 ).

\section{DISCUSSION}

A range of materials including autologous pericardium, porcine pulmonary valves, Dacron grafts, mechanical valves, bovine jugular veins, and homografts have been used for RVOT reconstruction. Porcine pulmonary valves have been fraught with early degeneration and in some cases have caused pulmonary stenosis. ${ }^{13}$ Complications from Dacron grafts include obstruction owing to a thick neointimal peel that requires explantation. ${ }^{14}$ Mechanical valves, albeit durable, require anticoagulation. ${ }^{15}$ Early degeneration and calcification are inevitable complications in commonly used homografts and bovine jugular veins. ${ }^{13}$ Unfortunately, their long-term availability and durability are unsatisfactory. ${ }^{13-15}$

Recently, late complications of RVOT reconstruction have been reported and include arrhythmias, heart failure, sudden death, and the need for repeat RVOT reconstruction as a result of right ventricular dysfunction, stenosis of the RVOT, and, most important, the deleterious effects of pulmonary regurgitation. ${ }^{16-18}$ A better prosthetic valved conduit or patch that is readily available and will be reliable for a long time is needed. Even homografts and bovine jugular veins used as valved conduits have complications owing to pulmonary insufficiency and have higher reoperation rates as compared with our ePTFE valves. ${ }^{13,19,20}$

We previously mentioned the good biocompatibility of ePTFE, as well as its microporous structure, which impedes cellular penetration. To enhance the function of the ePTFE valve, we developed a fan-shaped cusp, which has a long margin and curve to make a large coaptation zone. This more closely approximates the configuration of the natural semilunar valve. ${ }^{8}$ The fan-shaped ePTFE valve has demonstrated satisfactory results ${ }^{1,7}$; however, some fan-shaped valves were prone to sticking in the open position. ${ }^{6}$ In ePTFE valves that were stuck in the open position, the cause was not calcification or sclerosis but an inadequate closure effect. ${ }^{6}$ Therefore, we developed a bulging sinus on the 
Conduit

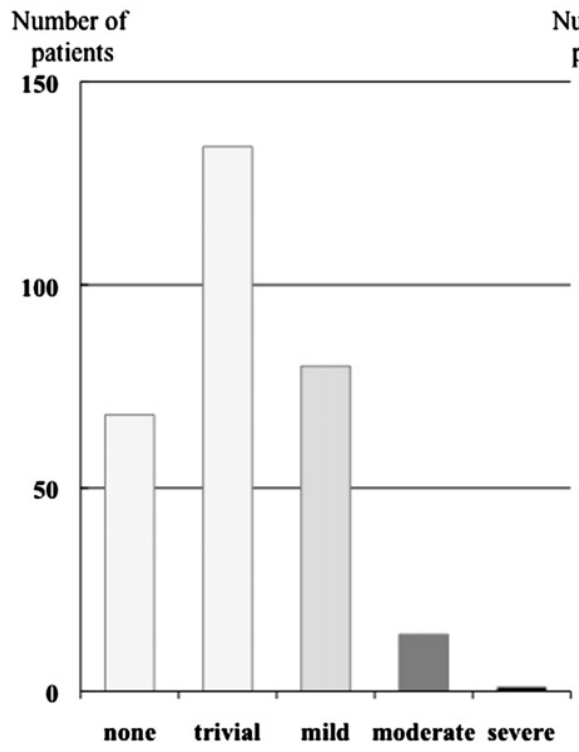

Patch

Number of

patients

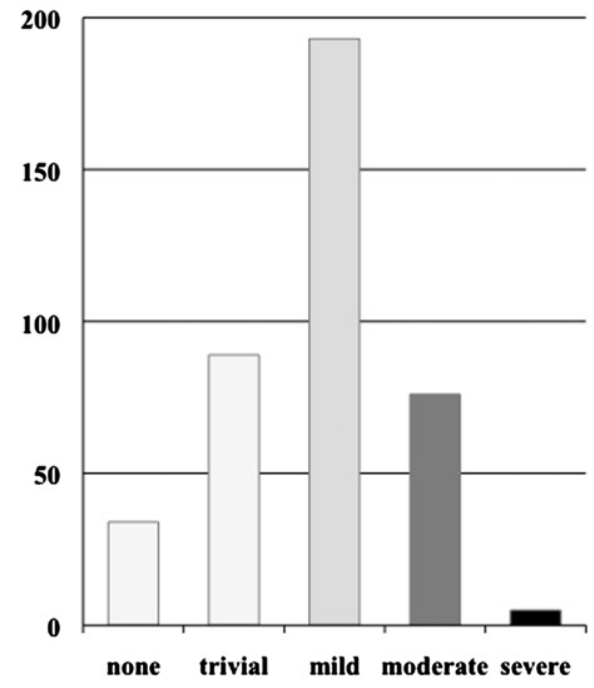

FIGURE 3. Pulmonary regurgitation.

conduits and patches in light of the vortex flow along the sinus of Valsalva. ${ }^{9}$ Ohta and coworkers ${ }^{21}$ reported the effect of the sinus of Valsalva on the closing motion of bileaflet prosthetic heart valves. The vortex flow in the sinus of Valsalva pushes the leaflet closed, and the valve starts the closing motion earlier than the prosthetic valve as the forward flow decelerates. This closing mechanism is thought to decrease backflow during valve closure, like a natural seminular valve. Bulging sinuses demonstrated the same closing mechanisms in engineering experiments using a pediatric right heart circulation model. ${ }^{22} \mathrm{~A}$ high-speed video camera was used to visualize leaflet motion and streamlines. Existence of bulging sinuses demonstrated a lower pressure gradient through the valves, a larger effective opening area, a faster response of valve movement, a lower energy loss at the valve, and less regurgitant flow at the valve. In addition,

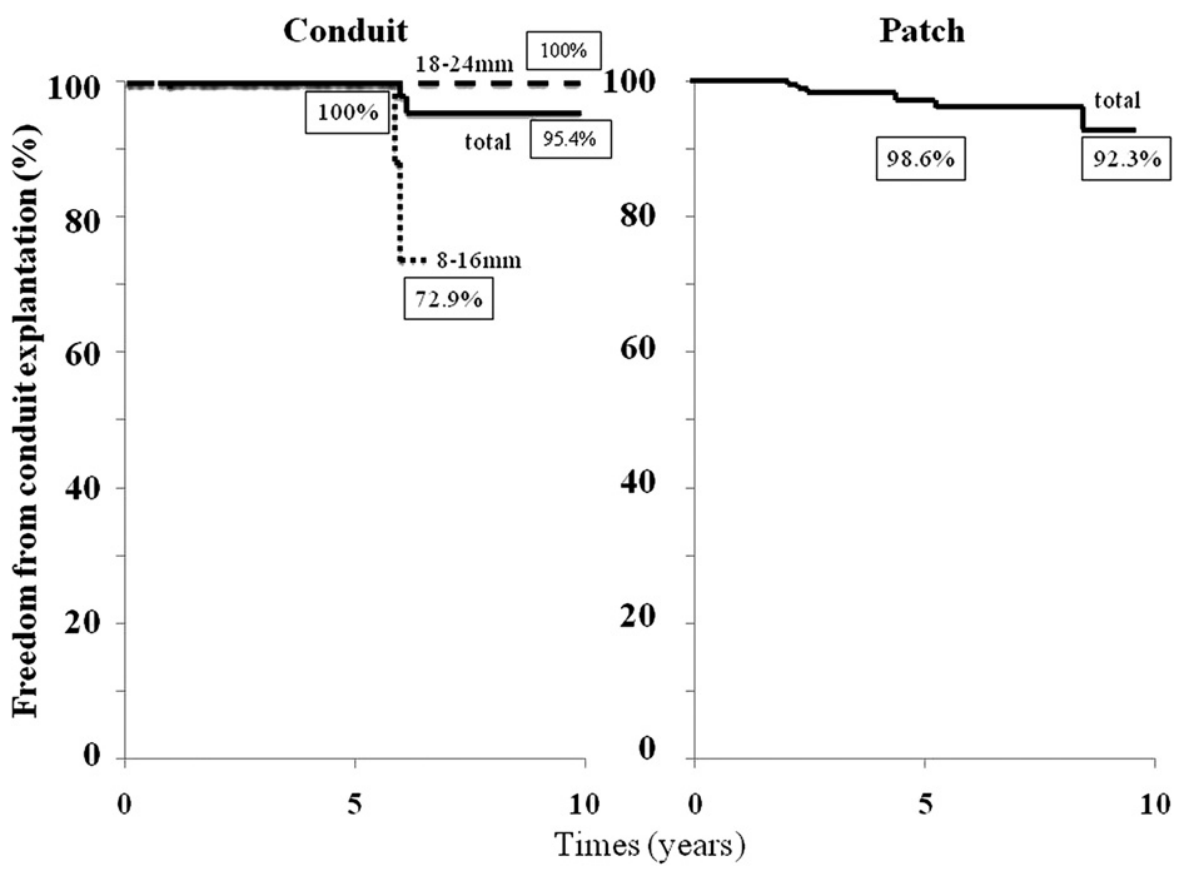

FIGURE 4. Kaplan-Meier freedom from reoperation. 


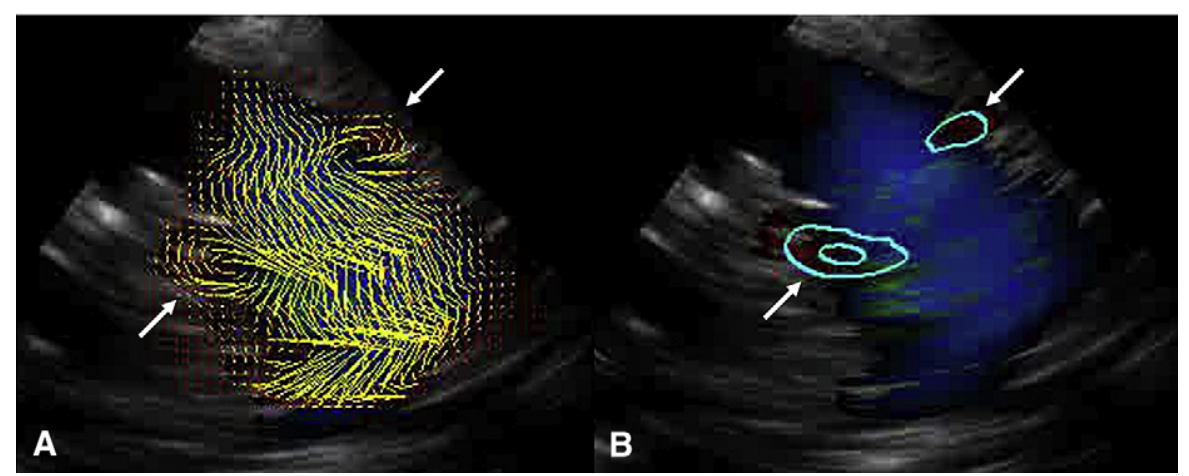

FIGURE 5. Echocardiographic evaluation of the vortex flow along the bulging sinuses. A, White arrows indicate velocity vector at bulging sinuses of the ePTFE conduit. B, White arrows indicate counterclockwise vortex flow at bulging sinuses of the ePTFE conduit. ePTFE, Expanded polytetrafluoroethylene.

existence of fan-shaped valves showed a lower pressure gradient and less regurgitant flow. The combination of a bulging sinus and a fan-shaped valve experimentally demonstrated the best valve function to prevent pulmonary regurgitation as well as stenosis. ${ }^{22}$ Vortex flow along the bulging sinuses of the ePTFE conduit was certainly confirmed during the late ejection period by echo-dynamography (Aloka, Tokyo, Japan) (Figure 5).

In addition, surgical techniques are important in preventing pulmonary insufficiency. Turrentine and colleagues ${ }^{7}$ adopted a transannular ePTFE monocuspid patch in RVOT reconstruction. They reported that a bullet-shaped piece of 0.1-mm ePTFE is fashioned by placing the material in the ventricular portion of the opening and allowing it to lay flush along the ventricular walls and conal septum, thereby maximizing surface area coaptation. We think this design of the valve is too big to close naturally. Most of the valve is covered inside the right ventricle; in other words, the valve is so long that a large amount of energy is necessary to close it, which predisposes the valve to becoming fixed in the open position, as well as increasing its risk of pannus formation. In this regard, the design of our fan-shaped valve is not long enough to move the hole of the valve. Furthermore, the vortex flow along the bulging sinuses can lead the valve to close all the time.

In cases of tricuspid conduit replacement of the RVOT, 1 of the cusps is placed in the greater curvature of the RVOT and the other 2 cusps are placed in the lesser curvature in the same location as the natural semilunar valves (Video 2). This allows for the most hydrodynamically advantageous placement. That is, this positioning is considered appropriate because of the fast flow velocity in the greater curvature of the RVOT. The number of patients with bicuspid valved conduits was few, so we cannot draw a comparison between bicuspid valved conduits and tricuspid valved conduits. However, in our series, no leaflet was completely fixed in the open position and the design appeared to prevent pulmonary insufficiency. Therefore, tricuspid valves might be ideal for achieving optimal long-term valve function.
In group P, 81 (20.4\%) patients had at least a moderate amount of regurgitation. This degree of regurgitation was higher than that of group C $(5.0 \%)$. This might be due to the quality of the native valve, which makes up the posterior wall of the RVOT. In the case of severe pulmonary stenosis like a fish-mouth pulmonary valve, we prefer a conduit repair for RVOT reconstruction because the native valves are not expected to have sufficient valve function.

It is a controversial problem to choose an optimal size of the conduit. ${ }^{23,24}$ Invariably, patients who had a smaller conduit had a higher likelihood of needing a reoperation. An optimal conduit size might prolong the interval to the subsequent operations. Interestingly, it has been reported that oversized allografts do not improve durability. ${ }^{23,24}$ In our series, conduit size was determined to be about $140 \%$ of the normal size of the pulmonary annulus as calculated by the formula of Rowlatt. ${ }^{12}$ Under this strategy, the freedom from reoperation was low, even in the group with small conduit diameters $(8-16 \mathrm{~mm})$. Furthermore, younger age is a risk factor for conduit dysfunction. We propose that a $\mathrm{Z}$ value of 2.4 can be a criterion for determining conduit size. It is striking that the patients who received conduit sizes over $18 \mathrm{~mm}$ did not need reoperation.

Although only 2 patients who underwent RVOT reconstruction using $12-\mathrm{mm}$ conduits needed reoperation, the freedom from reoperation was $72.9 \%$ at 6 years in the small conduit group (conduit diameter, 8-16 mm). This was because the small conduits were developed later and so the mean follow-up time of patients with small conduits was $2.9 \pm 1.8$ years (the longest follow-up was 6.8 years), which is a relatively short time period. However, a $72.9 \%$ rate of freedom from reoperation at 6 years is an adequate result.

With the growth of the adult population with congenital heart disease, pregnancy becomes an issue because of volume overload of the right ventricle in female patients. In our series, 2 female patients who underwent RVOT reconstruction using ePTFE valved conduits were delivered of babies. One of them had a vaginal delivery. The conduit was able to protect the right ventricle so that she could 
tolerate the higher pressures during vaginal delivery. Therefore, these valves might be suitable for female patients who want to have children.

We have to construct these valves ourselves, and ePTFE is slightly stiffer for suturing than homografts and bovine jugular veins. However, ePTFE valves can be made to any desired size, are easy to construct, have good biocompatibility, and are relatively inexpensive. Although further follow-up is necessary, especially for the small conduits, the combined effectiveness of the ePTFE conduits and patches with bulging sinuses and the fan-shaped ePTFE valves have a low freedom from reoperation and prevent pulmonary insufficiency, making it a promising material for RVOT reconstruction.

\section{CONCLUSION}

ePTFE has good biocompatibility, making it an ideal material for surgical prostheses. A newly developed fan-shaped valve with bulging sinuses on ePTFE conduits and patches has beneficial effects on the long-term valve function in RVOT reconstruction. These valves can accomplish excellent midterm outcomes even with smaller-sized conduits and can be a promising material for RVOT reconstruction.

We are grateful to all the institutions that were included in this study for providing data for this manuscript.

\section{References}

1. Yamagishi M, Emmoto T, Wada Y, Oka T. Pulmonary reconstruction in the Ross procedure: combined autologous aortic and polytetrafluoroethylene valve. J Thorac Cardiovasc Surg. 1998;116:1076-7.

2. Ando M, Takahashi Y. Ten-year experience with handmade trileaflet polytetrafluoroethylene valved conduit used for pulmonary reconstruction. J Thorac Cardiovasc Surg. 2009;137:124-31.

3. Takabayashi S, Kado H, Shiokawa Y, Fukae K, Nakano T. Modified Ross procedure using a conduit with a synthetic valve. Eur J Cardiothorac Surg. 2004;26: 1087-91.

4. Koh M, Yagihara T, Uemura H, Kagisaki K, Hagino I, Ishizaka T, et al. Longterm outcome of right ventricular outflow tract reconstruction using a handmade tri-leaflet conduit. Eur J Cardiothorac Surg. 2005;27:807-14.

5. Turrentine MW, McCarthy RP, Vijay P, McConnell KW, Brown JW. PTFE monocusp valve reconstruction of the right ventricular outflow tract. Ann Thorac Surg. 2002;73:871-80.

6. Yamagishi M, Kurosawa H, Nomura K, Kitamura N. Fan-shaped expanded polytetrafluoroethylene valve in the pulmonary position. J Cardiovasc Surg (Torino). 2002;43:779-86.

7. Turrentine MW, McCathy RP, Vijay P, McConnell KW, Brown JW. PTFE monocusp valve reconstruction of right ventricular outflow tract. Ann Thorac Surg. 2002;73:871-80.

8. Yamagishi M, Kurosawa H. Outflow reconstruction of tetralogy of Fallot using a Gore-Tex valve. Ann Thorac Surg. 1993;56:1414-7.

9. Miyazaki T, Yamagishi M, Nakashima A, Fukae K, Nakano T, Yaku H, et al. Expanded polytetrafluoroethylene valved conduit and patch with bulging sinuses in right ventricular outflow tract reconstruction. J Thorac Cardiovasc Surg. 2007; 134:327-32.

10. Daubeney PE, Blackstone EH, Weintraub RG, Slavik Z, Scanlon J, Webber SA. Relationship of the dimension of cardiac structures to body size: an echocardiographic study in normal infants and children. Cardiol Young. 1999;9:402-10.

11. Kirklin JW, Blackstone EH, Jonas RA, Kouchoukos NT. In: Kirklin JW, BarrattBoyes BG, eds. Cardiac surgery. 3rd ed. Edinburgh: Churchill Livingstone; 2004. Chapter 1, appendix 1G, p. 50.

12. Rowlatt UF, Rimoldi HJ, Lev M. The quantitative anatomy of the normal child's heart. Pediatr Clin North Am. 1963;10:499-588.
13. Boethig D, Thies WR, Hecker H, Breymann T. Mid term course after pediatric right ventricular outflow tract reconstruction: a comparison of homografts, porcine xenografts and Contegras. Eur J Cardiothorac Surg. 2005; 27:58-66.

14. Homann M, Haehnel JC, Mendler N, Paek SU, Holper K, Meisner H, et al. Reconstruction of the RVOT with valved biological conduits: 25 years experience with allografts and xenografts. Eur J Cardiothorac Surg. 2000;17:624-30.

15. Stulak JM, Dearani JA, Burkhart HM, Connolly HM, Warnes CA, Suri RM, et al. The increasing use of mechanical pulmonary valve replacement over a 40-year period. Ann Thorac Surg. 2010;90:2009-15.

16. Oechslin EN, Harrison DA, Harris L, Downar E, Webb GD, Siu SS, et al. Reoperation in adults with repair of tetralogy of Fallot: indications and outcomes. J Thorac Cardiovasc Surg. 1999;118:245-51.

17. Davlouros PA, Karatza AA, Gatzoulis MA, Shore DF. Timing and type of surgery for severe pulmonary regurgitation after repair of tetralogy of Fallot. Int $J$ Cardiol. 2004;97:91-101.

18. Meijboom FJ, Roos-Hesselink JW, McGhie JS, Spitaels SEC, van Domburg RT, Utens LMWJ, et al. Consequences of a selective approach toward pulmonary valve replacement in adult patients with tetralogy of Fallot and pulmonary regurgitation. J Thorac Cardiovasc Surg. 2008;135:50-5.

19. Dave H, Mueggler O, Comber M, Enodien B, Nikolaou G, Bauersfeld U, et al. Risk factor analysis of 170 single-Institutional Contegra implantations in pulmonary position. Ann Thorac Surg. 2011;91:195-203.

20. Sierra J, Christenson JT, Lahlaidi NH, Beghetti M, Kalangos A. Right ventricular outflow tract reconstruction: what conduit to use? Homograft or Contegra? Ann Thorac Surg. 2007;84:606-11.

21. Ohta Y, Kikuya S, Shimooka T, Mitamura Y, Yuhta T. Effect of sinus of Valsalva on the closing motion of bileaflet prosthetic heart valves. Artif Organs. 2000;24: 308-12.

22. Shiraishi Y, Suzuki I, Yabe S, Sugai TK, Yamada A, Kameyama T, et al. Engineering assessment of expanded polytetrafluoroethylene cardiac valve with bulging sinus. Jpn J Artif Organs. 2010;39:S-62.

23. Askovich B, Hawkins JA, Sower CT, Minich LLA, Tani LY, Stoddard G, et al. Right ventricle-to-pulmonary artery conduit longevity: is it related to allograft size? Ann Thorac Surg. 2007;84:907-12.

24. Kim WH, Min SK, Choi CH, Lee JR, Kim YJ, Bae EJ, et al. Follow-up of Shelhigh porcine pulmonic valve conduits. Ann Thorac Surg. 2007;84:2047-50.

\section{Discussion}

Dr Andres J. Schlichter (Buenos Aires, Argentina). I thank the authors for sending me the manuscript in advance. I sincerely congratulate them for this nice, neatly presented paper, which I really enjoyed. It addresses an old and recurrent problem with conduits. The patients usually outgrow them or their condition tends to deteriorate in the years after the so-called correction of the malformations. Really, no procedure using a conduit to connect the right ventricle to a pulmonary artery is a correction of the disease. It is a palliation.

Our group has addressed this problem since 1983 with autologous pericardial valved conduits. These have been shown to increase in diameter with the growth of the patient, but unfortunately, their valvular function has a short life. The ePTFE conduit here shown constructed with bulging sinuses follows the idea outlined by Leonardo da Vinci more than 500 years ago for the mechanism of closure of the sigmoid valves.

Apparently, the conduit here presented has a longer functioning valvular durability, and no degeneration has yet been demonstrated, as opposed to homografts and other xenografts. The fanshaped valves with vortex-like flow are a great improvement.

It is really surprising that even the smaller-sized conduits had a relatively long follow-up time, some 5 years, before needing explantation. This is more notable in the smallest sizes, 8 and $10 \mathrm{~mm}$, which we all would presume to become obstructive very soon after implantation. The indication for replacement for the conduit was 
mostly for obstruction, with pressure gradients of $50 \mathrm{~mm} \mathrm{Hg}$. Maybe you should have divided the conduits into 3 groups: one from 8 to $14 \mathrm{~mm}$ ( 20 patients), a second, $16 \mathrm{~mm}$ to $18 \mathrm{~mm}$, and a third, $18 \mathrm{~mm}$ and larger. Had you done so, do you think that the smaller conduits would have a significantly shorter life than the 6-year freedom from reoperation you had for your first group?

Dr Miyazaki. I appreciate your comment and I would like to answer your question. As you pointed out, problems with RVOT reconstruction are conduit stenosis, lack of growth potential, and, most important, the pulmonary regurgitation that will be the late cause of right ventricular dysfunction. An autologous pericardial valved conduit is an ideal material from the standpoint of growth potential. However, we have used autologous pericardial valved conduits that did not maintain the valve function for a long time, and we could not identify whether the autologous pericardium had a growth potential or not. In addition, unfortunately, autologous pericardial valves have been fraught with early degeneration and in some cases have caused pulmonary stenosis. Furthermore, because of legal problems, as well as particular regional reasons, homograft and bovine jugular veins are unavailable in our country. Therefore, we have developed handmade ePTFE valves.

To answer your first question: When dividing patients into 3 groups, the freedom from reoperation at 6 years in the smaller conduit $(8-14 \mathrm{~mm})$ is $60 \%$, in the medium-sized conduit $(16-18 \mathrm{~mm})$ $100 \%$, and larger conduit (20-24 mm) $100 \%$. However, small infants cannot escape from the smaller conduit implantation, and I think that this result is significantly better than the result of small-sized homografts and is equivalent to or better than the result with the Contegra valved conduit (Medtronic, Inc, Minneapolis, Minn). Moreover, the reason for the reoperation was patient somatic growth, not the dysfunction of the valved conduit.

We decided the indication for conduit replacement was a pressure gradient of $50 \mathrm{~mm} \mathrm{Hg}$. However, we try to intervene earlier if we think that the patient can receive a big enough conduit to prevent right ventricular dysfunction, even if the pressure gradient is less than $50 \mathrm{~mm} \mathrm{Hg}$.

Dr Schlichter. That is a very nice answer.

Regarding the patches, you state that on some occasions you reconstruct the posterior wall with autologous pericardium and then complete the outflow tract by placing the ePTFE valve anteriorly.

My second question is in 2 parts. First, do you suture ePTFE valves on the posterior right ventricular-pulmonary artery continuity, too? Second, if you do not suture a valve on the posterior aspect of the outflow and you use only a monocusp on the patch, do you suspect that this may be the cause for a higher percent of pulmonary incompetence in the patients in the patch group as compared with the conduit group? The anterior cusps may coapt with the posterior wall at the time of surgery, but when the posterior aspect dilates or grows, it may be foreseen that the ePTFE valves will not coapt any more.

Dr Miyazaki. To answer the first question, yes, we sutured a bicuspid fan-shaped ePTFE valve to the posterior pericardial right ventricle-pulmonary artery continuity. However, we do not have data on how to reconstruct the posterior right ventricle-pulmonary artery continuity at the other institutions involved in this study.
To answer the second question, when we reconstruct the RVOT using a monocuspid patch and valveless autologous pericardium, I suspect this might be the cause for the higher percentage of pulmonary incompetence.

We think that the growth potential is the other important factor for small children, and we are using the autologous material for the posterior wall reconstruction. The majority of patients who need RVOT reconstruction with autologous pericardium in the posterior wall and the monocuspid patch in the anterior wall had more complex anatomy such as truncus arteriosus. However, as you indicated, the growing or dilating posterior wall may end up with noncoapting leaflets that were initially working well, so we have developed a fan-shaped valve that has a long circular margin that possesses a large coaptation zone.

Furthermore, we used patches in cases of tetralogy of Fallot or other congenital cardiac disorders with a narrow pulmonary annulus. In our series, the patients with patches had a greater chance to have a moderate amount of regurgitation in the long-term than the patients with conduits. This might be due to the quality of the native valve, which makes up the posterior wall of the RVOT. The native valves are very likely to degenerate and cause pulmonary stenosis. When the ePTFE valve leaflets are sutured on the autologous posterior wall, they are not expected to provide longlasting good valve function because of the lack of sinuses.

In addition, in the case of severe pulmonary stenosis like a fishmouth pulmonary valve, we prefer a conduit for RVOT reconstruction, because the native valves are not expected to have sufficient valve function.

Dr Schlichter. My last question is this: Are you expecting these ePTFE $0.1-\mathrm{mm}$ membrane valves to have a very long functioning life or are you suspecting that these will deteriorate with time, too? I think the incorporation of a longer-lasting valvular function with the ePTFE fan-shaped valves with bulging sinuses and vortex-like flow are really an important improvement. Unfortunately, although an excellent material, PTFE still does not grow, so that the smallsized conduits will still have to be replaced at least once.

I want to commend your group for the important work done in this field.

Dr Miyazaki. Indeed, we have used fan-shaped ePTFE valves without bulging sinuses for over 20 years, and most patients still have demonstrated a good motion of the leaflet valve. We expect the $0.1-\mathrm{mm}$ ePTFE membrane valves to have a long valve function thanks to the bulging sinuses.

Furthermore, Japanese are relatively small built, so we think an 18-mm conduit for female and a 22-mm conduit for male subjects could stand long use. Although further follow-up will be necessary, there is a high possibility that reoperation owing to the patient's growth and body weight gain is avoidable in both conduit sizes.

Dr Thoralf Sundt (Boston, Mass). I have a quick question about biocompatibility. You mentioned the potential for tissue ingrowth. I am surprised that tissue ingrowth does not make the valves stiff. What is the character of the tissue ingrowth to the ePTFE?

Dr Miyazaki. We have no evidence of pannus formation and calcification that make the valves stiff. I think the reason is that the valves keep in motion thanks to the bulging sinuses. 